Revista Brasileira de Agricultura Irrigada v.13, nº.1, p. 3226 - 3235, 2019

ISSN 1982-7679 (On-line)

Fortaleza, CE, INOVAGRI - http://www.inovagri.org.br

DOI: $10.7127 /$ rbai.v13n100993

Protocolo 993.19 - 16/07/2018 Aprovado em 03/04/2019

\title{
VARIAÇÃO DE VAZÃO DEVIDO A FERTIRRIGAÇָ̃̃O COM MACRO E MICRONUTRIENTES EM UM SISTEMA DE IRRIGAÇÃ̃O POR GOTEJAMENTO
}

\author{
Fernando Nobre Cunha ${ }^{1}$, Marconi Batista Teixeira ${ }^{2}$, Carlos Ribeiro Rodrigues ${ }^{3}$, Giovani Santos \\ Moraes $^{4}$, Igor Olacir Fernandes Silva ${ }^{5}$, José Henrique Rodrigues Dias ${ }^{6}$
}

\begin{abstract}
RESUMO
As obstruções químicas geralmente resultam da precipitação de sais de cálcio, magnésio, ferro ou manganês, formando incrustações que podem provocar o entupimento dos emissores. Objetivou-se assim avaliar a influência da fertirrigação com macro e micronutrientes em um sistema de irrigação por gotejamento. O experimento foi realizado em uma casa de vegetação instalada na área experimental do IFGoiano - Campus Rio Verde. A casa de vegetação é constituída de cobertura de filme plástico polietileno transparente, de 150 micras e laterais fechadas, com tela tipo sombrite com $30 \%$ de interceptação. O delineamento experimental utilizado é em blocos ao acaso, analisado em esquema fatorial $3 \times 4$, com três repetições; sendo o tratamento 1 (molibdato de amônio, cloreto de magnésio e sulfato de amônio), o tratamento 2 (nitrato de cálcio, ácido bórico e sulfato de zinco) e o tratamento 3 (sulfato de cobre, cloreto de manganês e sulfato de ferro) e quatro tempos de funcionamento $(200,400,600$ e 800 h). Foi utilizado um tubo gotejador com vazão nominal de 2,3 L $\mathrm{h}^{-1}$, diâmetro nominal $16 \mathrm{~mm}$, pressão de operação 100 a $350 \mathrm{kPa}$ e espaçamento entre emissores de 0,5 m. Depois de tabulados os dados, foram determinados: vazão, vazão relativa e coeficiente de uniformidade de Christiansen. A fertirrigação com sulfato de cobre, cloreto de manganês e sulfato de ferro, e a fertirrigação com molibdato de amônio, cloreto de magnésio e de sulfato de amônio provocaram maiores alterações na vazão e na vazão relativa dos emissores.
\end{abstract}

Palavras-chave: sulfato de ferro, fertilizante, obstrução

\section{FLOW VARIATION DUE TO FERTIRRIGATION WITH MACRO AND MICRONUTRIENTS IN A DRIP IRRIGATION SYSTEM}

\author{
ABSTRACT \\ Chemical obstructions usually result from the precipitation of calcium salts, magnesium, iron or \\ manganese, forming fouling that can cause the obstructions of emitters. The objective of this study

\footnotetext{
${ }^{1}$ Pós-doutorando, Pesquisador, IFGoiano - Campus Rio Verde, e-mail: fernandonobrecunha@hotmail.com

${ }^{2}$ Doutor, Professor, IFGoiano - Campus Rio Verde, e-mail: marconibt@gmail.com

${ }^{3}$ Doutor, Professor, IFGoiano - Campus Rio Verde, e-mail: carlos.rodrigues@ifgoiano.edu.br

${ }^{4}$ Mestrando, IFGoiano - Campus Rio Verde, e-mail: giovanisantosrv@ gmail.com

${ }^{5}$ Mestrando, IFGoiano - Campus Rio Verde, e-mail: igorolacirrv95@gmail.com

${ }^{6}$ Graduando em Agronomia, IFGoiano - Campus Rio Verde, e-mail: zehenrique_dias@hotmail.com
} 
was to evaluate the influence of fertirrigation with macro and micronutrients in a drip irrigation system. The experiment was realized in a greenhouse located in the experimental area of the IFGoiano - Rio Verde Campus. The greenhouse consists of roof of film plastic transparent polyethylene, of 150 microns and closed sides, with screen with $30 \%$ interception. The experimental design used randomized block, analyzed in factorial scheme $3 \times 4$, with three replications; with treatment 1 (ammonium molybdate, magnesium chloride and ammonium sulfate), treatment 2 (calcium nitrate, boric acid and zinc sulphate) and treatment 3 (copper sulphate, manganese chloride and iron sulphate) and four operating times (200, 400, 600 and $800 \mathrm{~h})$. Used a drip tube with nominal flow of $2.3 \mathrm{~L} \mathrm{~h}^{-1}$, nominal diameter $16 \mathrm{~mm}$, operating pressure 100 to $350 \mathrm{kPa}$ and spacing between emitters of $0.5 \mathrm{~m}$. After of tabulated the data, were determined the flow, relative flow and coefficient of uniformity of Christiansen. Fertirrigation with copper sulphate, manganese chloride and iron sulfate and fertirrigation with ammonium molybdate, magnesium chloride and ammonium sulfate caused major alterations in the flow and the relative flow of the emitters.

Keywords: iron sulphate, fertilizer, obstruction

\section{INTRODUÇÃO}

Sistemas de irrigação localizada são uma resposta para necessidade de se procurar novos sistemas de irrigação que sejam eficientes, que reduzam o consumo dos recursos hídricos e sobretudo, que minimizem os problemas de escassez de água, logo são alternativas tecnológicas promissoras, tanto no uso da água como na aplicação de fertilizantes solúveis, assumindo importância econômica e ambiental na atividade agrícola (BORSSOI et al., 2012; SOARES et al., 2012).

Um sistema de irrigação localizada bem projetado permite que se obtenha uniformidade de aplicação de água acima de 90\%; entretanto, com o seu intensivo uso, observa-se uma diminuição na uniformidade de emissão e um aumento na variação da vazão, ao longo do tempo (TEIXEIRA, 2006); também podem ocorrer problemas referentes ao entupimento dos emissores, os quais podem vir a ser mais expressivos em função das características do gotejador e da qualidade da água relacionada aos aspectos físicos, químicos e biológicos (SANTOS et al., 2003; SILVA et al., 2012).

As obstruções químicas geralmente resultam da precipitação de sais de cálcio, magnésio, ferro ou manganês, formando incrustações que podem bloquear, parcial ou completamente a passagem da água (BRAUER, 2010), consequentemente nos sistemas de irrigação localizada, os emissores apresentam alta suscetibilidade ao entupimento, prejudicando o funcionamento geral do sistema de irrigação, afetando suas características de operação e exigindo manutenções mais frequentes (BATISTA et al., 2013).

Objetivou-se assim avaliar a influência da fertirrigação com macro e micronutrientes em um sistema de irrigação por gotejamento.

\section{MATERIAL E MÉTODOS}

O experimento foi realizado em uma casa de vegetação instalada na área experimental do IFGoiano - Campus Rio Verde. A casa de vegetação é constituída de cobertura de filme plástico polietileno transparente, de 150 micras e laterais fechadas, com tela tipo sombrite com $30 \%$ de interceptação. As coordenadas geográficas do local de instalação são $17^{\circ} 48^{\prime} 28^{\prime \prime} \mathrm{S}$ e $50^{\circ} 53{ }^{\prime} 57^{\prime \prime} \mathrm{O}$, com altitude média de $720 \mathrm{~m}$ ao nível do mar. O clima da região é classificado conforme Köppen (2013), como Aw (tropical), com chuva nos meses de outubro a maio, e com seca nos meses de junho a setembro. A temperatura média anual varia de 20 a $35^{\circ} \mathrm{C}$ e as precipitações variam de 1.500 a $1.800 \mathrm{~mm}$ anuais.

O delineamento experimental utilizado foi em blocos ao acaso, analisado em esquema fatorial $3 \times 4$, com três repetições; sendo o tratamento 1 (molibdato de amônio, cloreto de 
magnésio e sulfato de amônio), o tratamento 2 (nitrato de cálcio, ácido bórico e sulfato de zinco) e o tratamento 3 (sulfato de cobre, cloreto de manganês e sulfato de ferro) e quatro tempos de funcionamento (200, 400, 600 e 800 h).

Foram aplicadas via fertirrigação as seguintes quantidades no tratamento 1: 0,12 g/1000 L de molibdato de amônio, 200 g/1000 $\mathrm{L}$ de cloreto de magnésio e $200 \mathrm{~g} / 1000 \mathrm{~L}$ de sulfato de amônio; no tratamento 2: 900 g/1000 L de nitrato de cálcio, 1,9 g/1000 L de ácido bórico e $1,15 \mathrm{~g} / 1000 \mathrm{~L}$ de sulfato de zinco; no tratamento 3: $0,12 \mathrm{~g} / 1000 \mathrm{~L}$ de sulfato de cobre, $4 \mathrm{~g} / 1000 \mathrm{~L}$ de cloreto de manganês e $400 \mathrm{~g} / 1000 \mathrm{~L}$ de sulfato de ferro. O sistema de irrigação possuía sistema de filtragem equipado com filtro de disco de 100 mesh para a retirada de partículas sólidas que porventura pudessem entrar no sistema.

Foi utilizado um tubo gotejador com vazão nominal de $2,3 \mathrm{~L} \mathrm{~h}^{-1}$, diâmetro nominal $16 \mathrm{~mm}$, pressão de operação 100 a $350 \mathrm{kPa}$ e espaçamento entre emissores de $0,5 \mathrm{~m}$ e o comprimento de cada linha de tubos gotejadores foi de $7 \mathrm{~m}$. À entrada das linhas gotejadoras, foi instalada uma tomada de pressão, permitindo que a cada medição de vazão a pressão fosse checada e, se necessária, ajustada àquela pré-estabelecida. Para isso, foi utilizado um manômetro de Bourdon com faixa de leitura de $0-4 \mathrm{Kgf} \mathrm{cm}^{-2}$.
Durante todo o período do ensaio foram realizadas as leituras de temperatura da água no reservatório de captação, com aplicação dos tratamentos com temperatura da água na faixa de $25^{\circ} \mathrm{C}\left(25^{\circ} \mathrm{C} \pm 1^{\circ} \mathrm{C}\right) . \mathrm{O}$ tempo de injeção dos fertilizantes foi em torno de $1 \mathrm{~h}$ como forma de garantir uma melhor aplicação dos fertilizantes, com base em uma diluição mínima.

Para injeção dos fertilizantes no sistema de irrigação optou-se por um injetor Venturi que realizava a sucção do fertilizante depois de dissolvidos em uma caixa reservatório com capacidade para $50 \mathrm{~L}$.

$\mathrm{O}$ procedimento para realização da leitura de vazão consistiu da pressurização do sistema, estabilização da pressão em $150 \mathrm{kPa}$ (+/- $5 \mathrm{kPa})$ no início da linha, posicionamento dos coletores sob os respectivos gotejadores com três segundos de defasagem e retirada dos coletores com a mesma sequência e defasagem de tempo após 5 min de coleta. Foi utilizado o método gravimétrico para a determinação do volume coletado de cada emissor. $\mathrm{O}$ monitoramento da vazão dos gotejadores, permitiu a obtenção da vazão média dos gotejadores, utilizando-se a equação 1 .

Depois de tabulados os dados de vazão, foram efetuados os cálculos da vazão relativa e do coeficiente de uniformidade de Christiansen, conforme as equações 2 a 3 .

$$
\begin{gathered}
q=\frac{V}{t} \\
Q_{r}=\frac{Q_{x, y}}{Q_{i}} \\
C U C=100\left\{1-\frac{\sum_{i=1}^{n}\left|X_{i}-\bar{X}\right|}{n \cdot \bar{X}}\right\}
\end{gathered}
$$


Em que:

$\mathrm{q}$ - vazão do gotejador, $\mathrm{L} \mathrm{h}^{-1}$;

$\mathrm{Q}_{\mathrm{r}}$ - vazão relativa, \%;

CUC - coeficiente de uniformidade de

Christiansen, em \%;

$\mathrm{Q}_{\mathrm{x}, \mathrm{y}}$ - vazão de um emissor $\mathrm{x}$ num dia y de irrigação, $\mathrm{L} \mathrm{h}^{-1}$;

$\mathrm{Q}_{\mathrm{i}}$ - vazão desse emissor no primeiro dia de irrigação, $\mathrm{L} \mathrm{h}^{-1}$;

$\mathrm{V}$ - volume, L;

$\mathrm{t}$ - tempo de coleta, h e

$S$ - desvio padrão da vazão dos gotejadores

usados, $\mathrm{L} \mathrm{h}^{-1}$;

$\bar{X}$ - vazão média dos gotejadores, em $\mathrm{L} \mathrm{h}^{-1}$;

$X_{i}$ - vazão de cada gotejador, em $\mathrm{L} \mathrm{h}^{-1}$;

$n$ - número de gotejadores observados.

Os dados obtidos foram submetidos à análise de variância pelo teste $\mathrm{F}$ ao nível de $5 \%$ de probabilidade, e em casos de significância, foi realizada a análise de regressão para os tempos de funcionamento, e as médias dos tratamentos com fertirrigação foram comparadas entre si pelo teste Tukey a $5 \%$ de probabilidade, utilizando-se o software estatístico SISVAR ${ }^{\circledR}$ (FERREIRA, 2011).

\section{RESULTADOS E DISCUSSÃO}

A interação fertirrigação e tempos de funcionamento do sistema de irrigação foi significativa ao nível de $5 \%$ de probabilidade, para a vazão, vazão relativa e o coeficiente de uniformidade de Christiansen (Tabela 1).

Efeitos da fertirrigação em relação aos tempos de funcionamento na vazão, na vazão relativa e no coeficiente de uniformidade de Christiansen do sistema de irrigação por gotejamento também foram observados por outros autores (CUNHA et al., 2013; CARVALHO et al., 2015).

Tabela 1. Resumo da análise de variância para as variáveis vazão, vazão relativa $\left(\mathrm{Q}_{\mathrm{r}}\right)$ e Coeficiente de uniformidade de Christiansen (CUC) da irrigação por gotejamento

\begin{tabular}{ccccc}
\hline \multirow{2}{*}{ FV $^{1}$} & GL & \multicolumn{3}{c}{ QM } \\
\cline { 3 - 5 } & 2 & Vazão & $\mathrm{Q}_{\mathrm{r}}$ & CUC \\
\hline FERT & 3 & $0,0263^{* *}$ & $47,12^{* *}$ & $25,31^{* *}$ \\
TFSI & 6 & $0,1001^{* *}$ & $183,26^{* *}$ & $69,99^{* *}$ \\
FERT*TFSI & 2 & $0,2255^{* *}$ & $4,56^{*}$ & $0,70^{*}$ \\
Bloco & 0,0008 & $406,82^{* *}$ & $42,37^{* *}$ \\
Resíduo & 22 & 1,38 & 1,43 & 0,24 \\
\hline CV & - & 1,35 & 0,52 \\
\hline
\end{tabular}

1Fertirrigação (FERT) e Tempos de funcionamento do sistema de irrigação (TFSI). Fonte de variação (FV), Grau de liberdade (GL), Quadrado médio (QM) e Coeficiente de variação (CV). ** e * significativo a 1 e 5\% de significância, respectivamente, ${ }^{\text {ns }}$ não significativo pelo teste $\mathrm{F}$ a $5 \%$ de significância.

A vazão no tempo de funcionamento de 200 h se manteve próximo a vazão nominal para todos os tratamentos, logo não houve diferença significativa entre os tratamentos 1 , 2 e 3 . Os tratamentos 1 e 3 , no tempo de funcionamento de $400 \mathrm{~h}$ apresentaram a menor vazão, com uma diferença de 3,3\% em relação ao tratamento 2 (Tabela 2). Ribeiro et al. (2010) observaram que a quantificação da vazão em sistemas de irrigação e/ou do próprio emissor é um parâmetro de extrema confiança para determinação das alterações, principalmente em função do entupimento dos emissores. 
Tabela 2. Vazão $\left(\mathrm{L} \mathrm{h}^{-1}\right)$ em diferentes tempos de funcionamento do sistema de irrigação por gotejamento

\begin{tabular}{lrrrrr}
\hline \multirow{2}{*}{ Tratamentos } & \multicolumn{5}{c}{ Tempo de funcionamento (h) } \\
\cline { 2 - 6 } & 200 & 400 & 600 & 800 \\
\hline T1 & $2,20 \mathrm{a}$ & $2,13 \mathrm{~b}$ & $2,04 \mathrm{a}$ & $1,97 \mathrm{~b}$ \\
T2 & $2,21 \mathrm{a}$ & $2,20 \mathrm{a}$ & $2,07 \mathrm{a}$ & $2,03 \mathrm{a}$ \\
T3 & $2,19 \mathrm{a}$ & $2,08 \mathrm{~b}$ & $1,94 \mathrm{~b}$ & $1,92 \mathrm{~b}$ \\
\hline
\end{tabular}

${ }^{1}$ Tratamento 1: molibdato de amônio, cloreto de magnésio e sulfato de amônio; Tratamento 2: nitrato de cálcio, ácido bórico e sulfato de zinco; e o Tratamento 3: sulfato de cobre, cloreto de manganês e sulfato de ferro. Médias com a mesma letra minúscula na coluna não indica diferença significativa pelo teste Tukey, a 5\% de significância.

No tempo de funcionamento de $600 \mathrm{~h}$ não houve diferença significativa na vazão entre os tratamentos 1 e 2, os quais apresentaram os melhores valores de vazão. No tempo de funcionamento de $800 \mathrm{~h}$ não houve diferença significativa na vazão entre os tratamentos 1 e 3 , os quais apresentaram uma diferença de $3 \%$ em relação ao tratamento 2 .

Carvalho et al. (2016) observaram redução de vazão de $4 \%$ quando foi realizada a fertirrigação com óxido de ferro, no tempo de funcionamento de aproximadamente $800 \mathrm{~h}$. A vazão relativa no tempo de funcionamento de 200 h não apresentou diferença significativa entre os tratamentos, apresentando uma vazão relativa média de aproximadamente $95,7 \%$ (Tabela 3). Nascimento et al. (2016) também não observaram alterações significativas na vazão relativa, nos tempos iniciais de funcionamento.

Tabela 3. Vazão relativa (\%)em diferentes tempos de funcionamento da irrigação por gotejamento

\begin{tabular}{lrrrr}
\hline \multirow{2}{*}{ Tratamentos } & \multicolumn{5}{c}{ Tempo de funcionamento (h) } \\
\cline { 2 - 6 } & 200 & 400 & 600 & 800 \\
\hline T1 & $95,72 \mathrm{a}$ & $92,68 \mathrm{~b}$ & $88,86 \mathrm{a}$ & $85,49 \mathrm{~b}$ \\
T2 & $96,10 \mathrm{a}$ & $95,84 \mathrm{a}$ & $89,83 \mathrm{a}$ & $88,13 \mathrm{a}$ \\
T3 & $95,33 \mathrm{a}$ & $90,38 \mathrm{c}$ & $84,40 \mathrm{~b}$ & $83,61 \mathrm{c}$ \\
\hline
\end{tabular}

${ }^{1}$ Tratamento 1: molibdato de amônio, cloreto de magnésio e sulfato de amônio; Tratamento 2: nitrato de cálcio, ácido bórico e sulfato de zinco; e o Tratamento 3: sulfato de cobre, cloreto de manganês e sulfato de ferro. Médias com a mesma letra minúscula na coluna não indica diferença significativa pelo teste Tukey, a 5\% de significância.

No tempo de funcionamento de $400 \mathrm{~h}$ o tratamento 3 apresentou a menor vazão relativa, indicando uma diferença de 2,3 e $5,5 \%$, para os tratamentos 1 e 2, respectivamente; já entre os tratamentos 1 e 2 , verificou-se uma diferença de $3,2 \%$.

No tempo de funcionamento de $600 \mathrm{~h}$ os tratamentos 1 e 2 apresentaram a maior vazão relativa, indicando uma diferença de $4,5 \%$, para o tratamento 3. No tempo de funcionamento de $800 \mathrm{~h}$ o tratamento 1 apresentou uma vazão relativa intermediário, indicando uma diferença de 2,6 e 1,9\%, para os tratamentos 2 e 3 , respectivamente; já entre os tratamentos 2 e 3 , verificou-se uma diferença de 4,5\%.Teixeira et al. (2014) observaram uma variação dos valores de vazão média e vazão relativa após cada tempo de funcionamento, principalmente devido a obstrução parcial dos emissores.

A uniformidade de água no tempo de funcionamento de $200 \mathrm{~h}$ se manteve sempre acima de 97,7\%, com destaque para a fertirrigação com os tratamentos 1 e 2 que apresentaram o maior coeficiente de uniformidade de Christiansen (CUC). O tratamento 3 apresentou o menor CUC, com uma diferença de até $1,6 \%$ em relação aos tratamentos 1 e 2 indicando um possível efeito negativo da fertirrigação com sulfato de cobre, cloreto de manganês e sulfato de ferro na uniformidade de aplicação (Tabela 4). 
Tabela 4. Coeficiente de uniformidade de Christiansen (\%) em diferentes tempos de funcionamento do sistema de irrigação por gotejamento

\begin{tabular}{lrrrrr}
\hline \multirow{2}{*}{ Tratamentos } & \multicolumn{5}{c}{ Tempo de funcionamento (h) } \\
\cline { 2 - 6 } & 200 & 400 & 600 & 800 \\
\hline T1 & $97,72 \mathrm{a}$ & $96,12 \mathrm{~b}$ & $93,16 \mathrm{~b}$ & $91,97 \mathrm{~b}$ \\
T2 & $98,28 \mathrm{a}$ & $97,59 \mathrm{a}$ & $94,19 \mathrm{a}$ & $93,14 \mathrm{a}$ \\
T3 & $96,68 \mathrm{~b}$ & $94,36 \mathrm{c}$ & $91,31 \mathrm{c}$ & $89,37 \mathrm{c}$ \\
\hline
\end{tabular}

${ }^{1}$ Tratamento 1: molibdato de amônio, cloreto de magnésio e sulfato de amônio; Tratamento 2: nitrato de cálcio, ácido bórico e sulfato de zinco; e o Tratamento 3: sulfato de cobre, cloreto de manganês e sulfato de ferro. Médias com a mesma letra minúscula na coluna não indica diferença significativa pelo teste Tukey, a 5\% de significância.

Vários fatores podem comprometer a uniformidade dos sistemas de irrigação localizada destacando-se, entre eles, o desequilíbrio de vazão, entupimento parcial ou total dos emissores (VIEIRA et al., 2004; CUNHA et al., 2014). No tempo de funcionamento de $400 \mathrm{~h} \mathrm{o}$ tratamento 3 apresentou o menor CUC, indicando uma diferença de 1,5 e $3,2 \%$, para os tratamentos 1 e 2, respectivamente. No tempo de funcionamento de $600 \mathrm{~h}$, houve diferença significativa na uniformidade entre todos os tratamentos com destaque para o tratamento 2 , que demonstrou uma diferença de aproximadamente $2,90 \%$ em relação ao tratamento 3 , tal desempenho foi confirmado no tempo de funcionamento de $800 \mathrm{~h}$ onde o tratamento 2 também apresentou o maior CUC, seguido do tratamento 1 e 3, apresentando uma diferença de até 3,80\%.
Os emissores submetidos à fertirrigação, apresentaram desempenho distintos quanto à variação de vazão, em parte devido à arquitetura de cada gotejador, que faz com que os níveis de entupimento se mostrem de forma heterogenia (CARVALHO et al., 2015).

A vazão em função do tempo de funcionamento se adequou ao modelo linear para os tratamentos 1,2 e 3, com $\mathrm{R}^{2}$ acima de $89 \%$ (Figura 1). Na Figura 1 pode ser observado o comportamento da vazão para cada tratamento em função do tempo de funcionamento.

Levando em consideração o tempo de funcionamento de 200 e $800 \mathrm{~h}$, observaram-se reduções na vazão de aproximadamente 10,90, 8,10 e $13,80 \%$, quando utilizaram-se na fertirrigação os tratamentos 1, 2 e 3 , respectivamente.

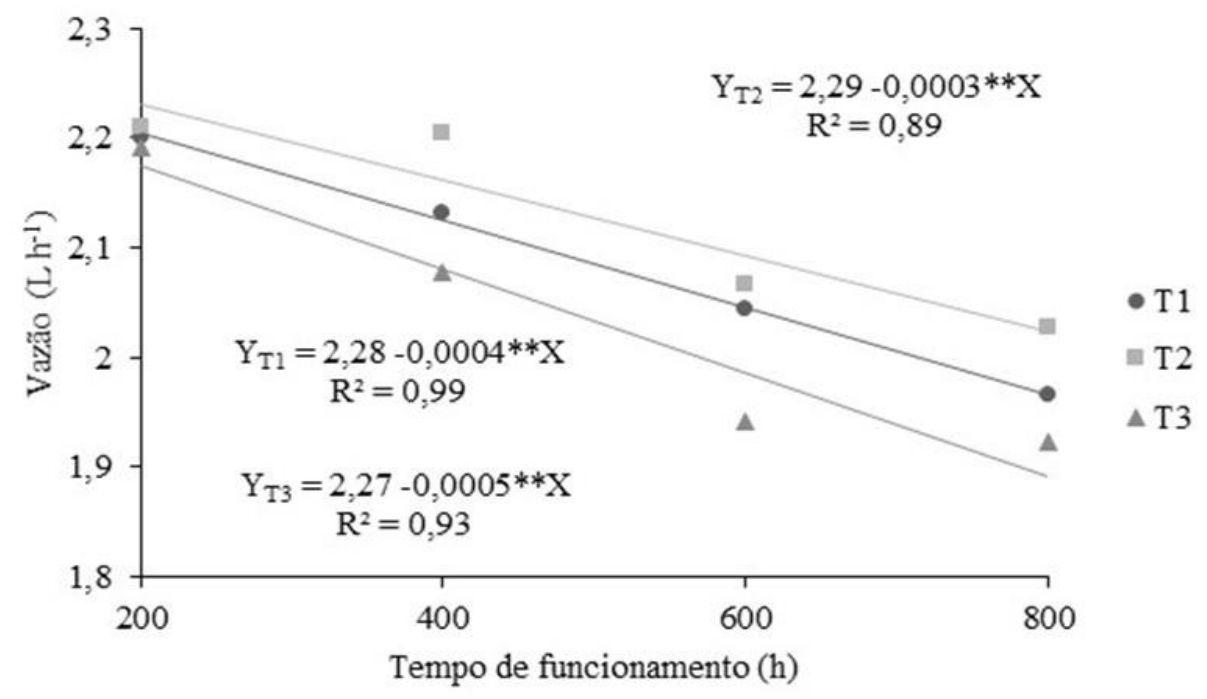

Figura 1. Vazão em função dos tempos de funcionamento para o Tratamento 1 (molibdato de amônio, cloreto de magnésio e sulfato de amônio), Tratamento 2 (nitrato de cálcio, ácido bórico e sulfato de zinco) e o Tratamento 3 (sulfato de cobre, cloreto de manganês e sulfato de ferro).

${ }^{* *} \mathrm{e}^{*}$ significativo respectivamente a $1 \%$ e $5 \%$ segundo teste $\mathrm{F}$. 
A deposição do material inicial quando em obstrução parcial tem pouca diferenciação na uniformidade, devido à redução de vazão de muitos emissores ainda permanecer discreta, sendo consequentemente mais preponderante para a determinação da obstrução total, pois a vazão neste caso é afetada de forma bastante significativa (CUNHA et al., 2014).

A vazão a cada aumento de $200 \mathrm{~h}$ no tempo de funcionamento apresenta um decréscimo de 3,60, 2,70 e 4,60\%, quando aplicado via água de irrigação o Tratamento 1 (molibdato de amônio, cloreto de magnésio e sulfato de amônio), Tratamento 2 (nitrato de cálcio, ácido bórico e sulfato de zinco) e o
Tratamento 3 (sulfato de cobre, cloreto de manganês e sulfato de ferro), respectivamente. Batista et al. (2011) também verificaram entre os tempos de funcionamento de 0 e $500 \mathrm{~h}$, reduções consideráveis na vazão dos gotejadores por causa da fertirrigação.

A vazão relativa em função do tempo de funcionamento se adequou ao modelo linear para todos os tratamentos, com $\mathrm{R}^{2}$ acima de $89 \%$ (Figura 2).

Considerando o tempo de funcionamento de 200 e $800 \mathrm{~h}$, observaram-se reduções na vazão relativa de aproximadamente 10,40, 9,00 e 12,40\%, quando utilizaram-se na fertirrigação os tratamentos 1,2 e 3 , respectivamente.

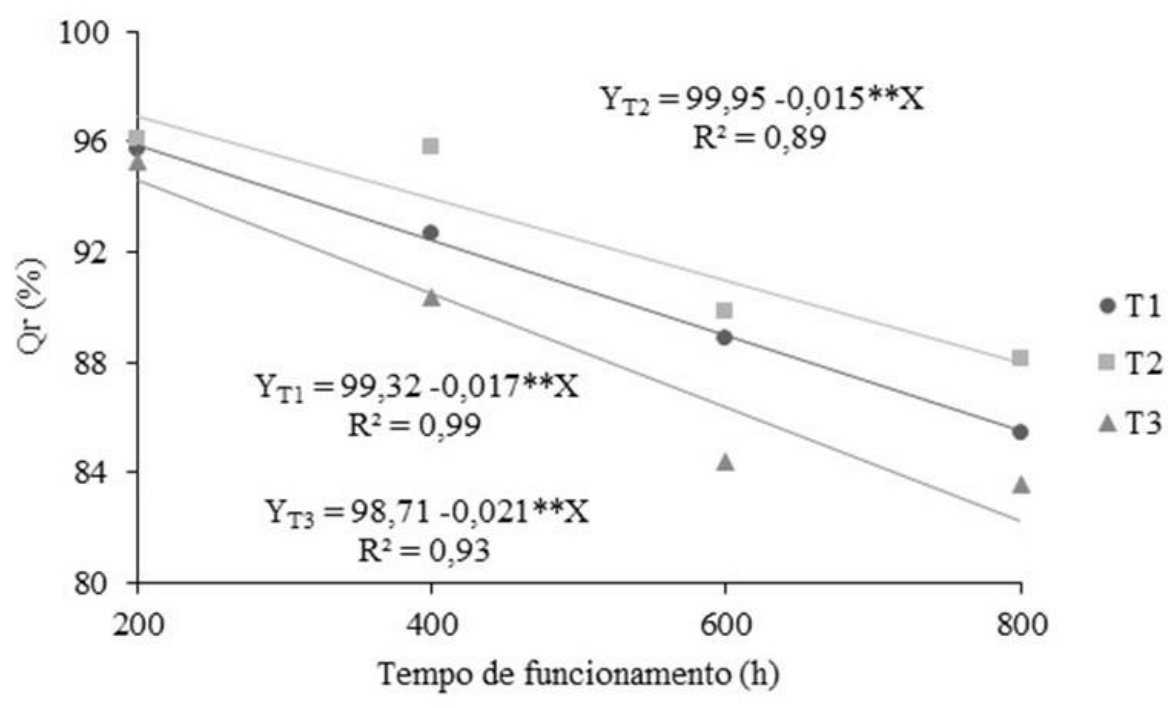

Figura 2. Vazão relativa em função dos tempos de funcionamento para o Tratamento 1 (molibdato de amônio, cloreto de magnésio e sulfato de amônio), Tratamento 2 (nitrato de cálcio, ácido bórico e sulfato de zinco) e o Tratamento 3 (sulfato de cobre, cloreto de manganês e sulfato de ferro).

$*^{* *} \mathrm{e}^{*}$ significativo respectivamente a $1 \%$ e $5 \%$, segundo teste $\mathrm{F}$.

Faria et al. (2004) observaram os maiores níveis de redução de vazão entre todos os modelos avaliados, com valores de vazão relativa variando de 0,31 a 0,67 , consequentemente no primeiro grupo a redução de vazão foi de 49 e $59 \%$, respectivamente, enquanto para o segundo grupo essa redução foi de 9 e $28 \%$, respectivamente.

A vazão relativa a cada aumento de 200 $\mathrm{h}$ no tempo de funcionamento, resultou num decréscimo de 3,50, 3,00 e 4,10\%, quando aplicado via água de irrigação no Tratamento
1 (molibdato de amônio, cloreto de magnésio e sulfato de amônio), Tratamento 2 (nitrato de cálcio, ácido bórico e sulfato de zinco) e o Tratamento 3 (sulfato de cobre, cloreto de manganês e sulfato de ferro), respectivamente. Segundo Brauer (2010) em estudos relacionados a dinâmica de entupimento de gotejadores em função da aplicação de água rica em ferro, observou que independente da dose utilizada ocorreu uma redução da vazão até as $800 \mathrm{~h}$ de funcionamento.

O CUC em função do tempo de funcionamento se adequou ao modelo linear, 
com $\mathrm{R}^{2}$ acima de $93 \%$ (Figura 3 ). Observou-se na Figura 3 o comportamento da uniformidade de aplicação para cada tratamento em função do tempo de funcionamento.

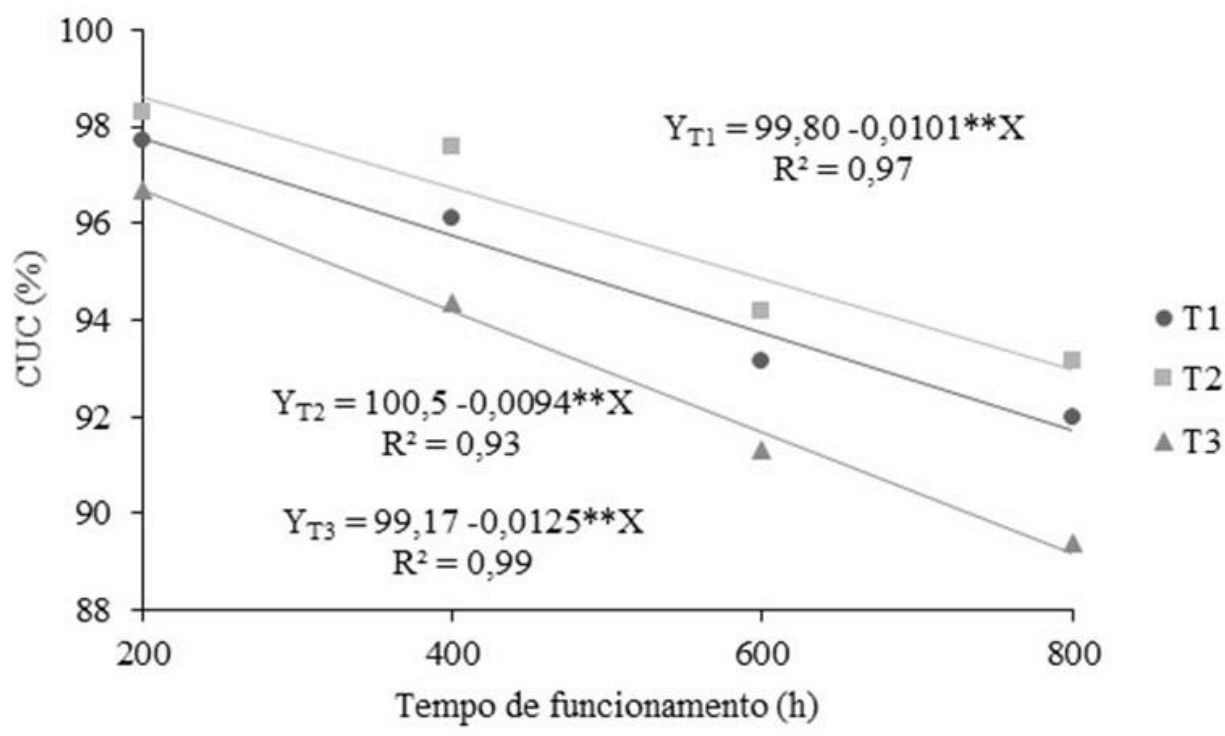

Figura 3. Coeficiente de uniformidade de Christiansen em função dos tempos de funcionamento para o Tratamento 1 (molibdato de amônio, cloreto de magnésio e sulfato de amônio), Tratamento 2 (nitrato de cálcio, ácido bórico e sulfato de zinco) e o Tratamento 3 (sulfato de cobre, cloreto de manganês e sulfato de ferro).

${ }^{* *} \mathrm{e}^{*}$ significativo respectivamente a $1 \%$ e $5 \%$, segundo teste $\mathrm{F}$.

Levando em consideração o tempo de funcionamento de 200 e $800 \mathrm{~h}$, observaram-se reduções no CUC de aproximadamente 6,10, 5,60 e 7,50\%, quando utilizaram-se na fertirrigação os tratamentos 1, 2 e 3 , respectivamente.

Ribeiro et al. (2012) observaram que quando os gotejadores são submetidos a condições extremas de uso, os emissores ficam mais susceptíveis a obstrução.

O CUC a cada aumento de $200 \mathrm{~h}$ no tempo de funcionamento resultou num decréscimo de 2,00, 1,90 e 2,50\%, quando o sistema de irrigação por gotejamento foi submetido a fertirrigação com o Tratamento 1 (molibdato de amônio, cloreto de magnésio e sulfato de amônio), Tratamento 2 (nitrato de cálcio, ácido bórico e sulfato de zinco) e o Tratamento 3 (sulfato de cobre, cloreto de manganês e sulfato de ferro), respectivamente.

Dalri et al. (2014) verificaram que os emissores em condições de fertirrigação provocaram injúrias aos emissores do ponto de vista de sua qualidade construtiva, consequentemente afetando a vazão.

\section{CONCLUSÕES}

A fertirrigação com sulfato de cobre, cloreto de manganês e sulfato de ferro, e a fertirrigação com molibdato de amônio, cloreto de magnésio e de sulfato de amônio provocaram maiores alterações na vazão e na vazão relativa dos emissores.

A utilização de nitrato de cálcio, ácido bórico e sulfato de zinco na fertirrigação proporcionou melhor uniformidade do sistema de irrigação.

\section{AGRADECIMENTOS}

Os autores agradecem ao Conselho Nacional de Desenvolvimento Científico e Tecnológico $(\mathrm{CNPq})$, à Coordenação de Aperfeiçoamento de Pessoal de Nível Superior (Capes), à Fundação de Amparo à Pesquisa do Estado de Goiás (FAPEG) e ao Instituto Federal Goiano - Campus Rio Verde, pelo apoio financeiro e estrutural. 


\section{REFERÊNCIAS BIBLIOGRÁFICAS}

BATISTA, R. O.; SOARES, A. A.; MOREIRA, D. A.; FEITOSA, A. P.; BEZERRA, J. M. Influência de diferentes qualidades de esgoto doméstico na vazão de gotejadores. Revista Caatinga, v. 24, n. 3, p. 128-134, jul.-set., 2011.

BATISTA, R.O.; OLIVEIRA, R.A.; SANTOS, D.B.; OLIVEIRA, A.F.M.; AZEVEDO, C.A.V.; MEDEIROS, S.S. Obstrução e uniformidade de aplicação em sistemas de irrigação por gotejamento aplicando-se efluente da suinocultura. Revista Brasileira de Engenharia Agrícola e Ambiental, n.17, v. 7, p.698-705, 2013. http://doi.org/10.1590/S141543662013000700002 .

BORSSOI, A. L.; VILAS BOAS, M. A.; REISDÖRFER, M.; HERNÁNDEZ, R. H.; FOLLADOR, F. A. C. Water application uniformity and fertigation in a dripping irrigation set. Engenharia Agrícola, v. 32, n. 4, p. 718-726, 2012. http://doi.org/10.1590/S0100-

69162012000400011.

BRAUER, R. L. Dinâmica de entupimento de gotejadores em função da aplicação de água rica em ferro. Dissertação (Mestrado) Universidade Estadual Paulista, Faculdade de Ciências Agronômicas, Botucatu, p.59, 2010.

CARVALHO, L. C. C.; COELHO, R. D.; TEIXEIRA, M. B.; CUNHA, F. N.; SILVA, N. F.; SOARES, F. A. L.; VIDAL, V. M.; MORAIS, W. A. Entupimento de emissores autocompensantes com aplicação de sulfato e óxido de ferro. Científica, v.44, n.3, p.385402, 2016. http://doi.org/10.15361/19845529.2016v44n3p385-402.

CARVAlHO, L. C. C.; COELHO, R. D.; TEIXEIRA, M. B.; SOARES, F. A. L.; CUNHA, F. N.; SILVA, N. F. Tubos gotejadores convencionais submetidos a aplicação de óxido de ferro via água com carga orgânica e sólidos suspensos. Revista
Brasileira de Agricultura Irrigada v.9, n.2, $\begin{array}{llll}\text { p. } & 32 \quad \text { - } & 41, & \end{array}$ http://doi.org/10.7127/rbai.v9n200273.

CUNHA, F. N.; OLIVEIRA, R. C.; SILVA, N. F.; MOURA, L. M. F.; TEIXEIRA, M. B.; GOMES FILHO, R. R. Variabilidade temporal da uniformidade de distribuição em sistema de gotejamento. Revista Brasileira de Agricultura Irrigada, v.7, n. 4, p. 248 - 257, 2013. http://doi.org/10.7127/rbai.v7n400177.

CUNHA, F. N.; SILVA, N. F.; TEIXEIRA, M. B.; CARVALHO, J. J.; MOURA, L. M. F.; SANTOS, C. C. Coeficientes de uniformidade em sistema de irrigação por gotejamento. Revista Brasileira de Agricultura Irrigada, v. $8, \quad$ p. $444-454, \quad 2014$. http://doi.org/10.7127/rbai.v8n600254.

DALRI, A B.; PALARETTI, L. F.; CRUZ, R. L.; ZANINI, J. R.; FARIA, R. T.; SANTOS, G. O. Entupimento de emissores enterrados sob a cultura da cana-de-açúcar após três anos de cultivo em condições fertirrigadas. Irriga, Edição Especial 01, p. 62-71, 2014. https://doi.org/10.15809/irriga.2014v1n1p62.

FARIA, L. F.; COELHO, R. D.; RESENDE, R. S. Variação de vazão de gotejadores de fluxo normal enterrados na irrigação de café. Eng. Agríc., v.24, n.3, p.589-602, 2004. http://doi.org/10.1590/S0100-

69162004000300011.

FERREIRA, D. F. Sisvar: a computer statistical analysis system. Ciência e Agrotecnologia, v. 35, n.6, p. 1039-1042, 2011 http://doi.org/10.1590/S141370542011000600001.

NASCIMENTO, R. C.; MEDEIROS, P. R. F. SANTOS, G. S.; TELES, E. C. P. V. A.; GONÇALVES, D. R.; MARTINS, A. P. F. Dinâmica da obstrução de emissores usados na cultura da uva utilizando água salina de poço subterrâneo. Irriga, v. 21, n. $3, \quad$ p. 491-502, 2016. 
https://doi.org/10.15809/irriga.2016v21n3p49 1-502.

RIBEIRO, P. A. A.; COELHO, R. D.; TEIXEIRA, M. B. Entupimento de tubos gotejadores convencionais com aplicação de cloreto de potássio (branco e vermelho) via duas qualidade de água. Revista Engenharia Agrícola, v.30, n.2, p.279-287, mar./abr. $2010 . \quad$ http://doi.org/10.1590/S010069162010000200010 .

RIBEIRO, P. A. A.; TEIXEIRA, M. B.; COELHO, R. D.; FRANCO, E. M.; DA SILVA, N. F.; CARVALHO, L. C. C.; ALVES, M. E. B. Gotejadores submetidos a condições críticas de qualidade da água. Irriga, Edição Especial, p. 368 - 379, 2012. https://doi.org/10.15809/irriga.2012v1n01p36 8.

SANTOS, C. G. F.; LIMA, V. L. A.; MATOS, J. A.; HAANDEL, A. C. V.; AZEVEDO, C. A. V. Efeito de uso de águas residuárias sobre a vazão de microaspersores. Revista Brasileira de Engenharia Agrícola e Ambiental, v.7, p.577- 580, 2003. http://doi.org/10.1590/S141543662003000300028.

SILVA, L. P.; SILVA, M. M.; CORREA, M. M.; SOUZA, F. C. D.; SILVA, E. F. F. Desempenho de gotejadores autocompensantes com diferentes efluentes de esgoto doméstico. Revista Brasileira de Engenharia Agrícola e Ambiental, v.16, 00001. p. $\quad 480-486, \quad 2012$,

http: doi.org/10.1590/S1415-

43662012000500003.

SOARES, J. I.; SAAD, J. C. C; VALNIR JÚNIOR, M. Determinação dos coeficientes de uniformidade e eficiência em um sistema de irrigação localizado por gotejamento superficial e subsuperficial na estação experimental de Barbalha - CE. UNESP, p.5, 2012.

TEIXEIRA, M. B. Efeitos de dosagens extremas de cloro e pH na vazão de gotejadores autocompensantes (irrigação localizada). Piracicaba: ESALQ, Tese (Doutorado)-Escola Superior de Agricultura "Luiz de Queiroz". 2006. 318 p.

TEIXEIRA, M. B.; COELHO, R. D.; CUNHA, F. N.; SILVA, N. F. Curva característica da vazão de gotejadores em diferentes temperaturas da água e ação do cloro ou ácido. Revista Brasileira de Agricultura Irrigada. v.8, $\mathrm{n}^{\circ} .3$, p. 220 233, 2014. http://doi.org/10.7127/ rbai.v8n300214.

VIEIRA， G.H.S.; MANTOVANI， E.C.; SILVA, J.G.F.; RAMOS, M.M.; SILVA, C.M. Recuperação de gotejadores obstruídos devido à utilização de águas ferruginosas. Revista Brasileira de Engenharia Agrícola e Ambiental, v.8, p.1-6, 2004. http://doi.org/10.1590/S1415-436620040001 